\title{
THE SHAPE, SIZE AND POSITION OF MENTAL FORAMEN IN HUMAN DRIED MANDIBLE IN THE KALABURAGI REGION
}

\section{Mohammad Khaleel Ahmed ${ }^{1}$, Syed Nazeer Ahmed ${ }^{* 2}$, Humaira Zainab ${ }^{3}$.}

${ }^{1}$ Associate Professor, Department of Anatomy, Shadan Institute of medical sciences, Hyderabad, Telangana, India.

${ }^{* 2}$ Associate Professor, Department of Anatomy, Khaja Banda Nawaz Institute of Medical Sciences, Faculty of Medicine, Khaja Banda Nawaz University, Gulbarga, Karnataka, India.

${ }^{3}$ Assistant Professor, Department of Anatomy, Khaja Banda Nawaz Institute of Medical Sciences, Faculty of Medicine Khaja Banda Nawaz University, Gulbarga, Karnataka, India.

\section{ABSTRACT}

Introduction: The mental foramen is a funnel-like opening located on the anterolateral aspect of body of the mandible which marks the termination of the mental canal. The orientation and position of the mental foramen is important in performing anesthetic block prior to clinical procedures in lower-anterior teeth and also to preserve the integrity of the mental nerve trunk in surgical interventions.

Materials and Methods: A total of 100 adult dry human mandibles were collected from the department of Anatomy, Khaja Banda Nawaz institute of medical sciences, Faculty of Medicine, Khaja Banda Nawaz University, Gulbarga, Karnataka. The size, shape and position of the right and left side of the mandible were recorded in $\mathrm{mm}$ by direct visual inspection and digital vernier calipers.

Results: The parameters which were considered in the present study were size, shape and position of the mental foramen. In the present study the common shape encountered was oval shape, and the common position was below the Apex of $2^{\text {nd }}$ PM which coincides with the study by AGARWAL \& GUPTA.

Discussion: Agarwal \& Gupta et al studied on 100 mandibles in gujarat population. Mean H.D was 3.33mm on right side and $3.25 \mathrm{~mm}$ on left side, mean V.D was $2.15 \mathrm{~mm}$ on right side and $2.13 \mathrm{~mm}$ on left side. The comparative study of the present study and the other authors is tabulated in the tables.

Conclusion: The present study enlightens and assist the maxillofacial and dental surgeons about the importance of size, shape and position of the mental foramen for nerve block. It also has impact on the studies done previously like Agarwal et all and others. Hence this knowledge can be used as a tool for the dental surgeons.

KEY WORDS: Mental foramen, position, nerve block.

Corresponding Author: Dr. Syed Nazeer Ahmed, Associate Professor, Department of Anatomy, Khaja Banda Nawaz Institute of Medical Sciences, Faculty of Medicine, Khaja Banda Nawaz University, Gulbarga, Karnataka, India. Mob:+918884588421 E-Mail: nazeer1715@gmail.com

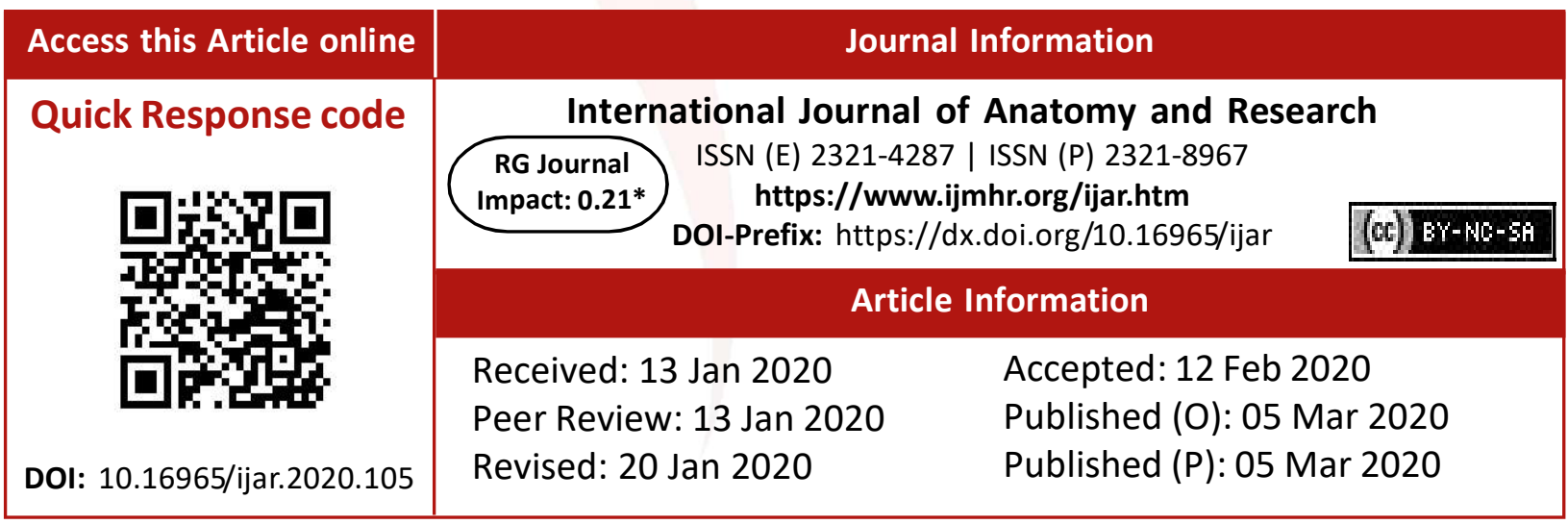

\section{INTRODUCTION}

The mental foramen is a funnel-like opening located on the anterolateral aspect of body of the mandible which marks the termination of the mental canal. The mental nerve and vessels radiate through the mental foramen and supply sensory innervation and blood supply to the soft tissues of the chin, lower lip and gingiva on the ipsilateral side of the mandible [1]. During the early prenatal life mental foramen is located in 
the alveolar bone between the primary canine and first molar. Therefore, it is speculated that positions other than the most common ones are due to a lag in prenatal development [2]. The orientation and position of the mental foramen is important in performing anesthetic block prior to clinical procedures in lower-anterior teeth and also to preserve the integrity of the mental nerve trunk in surgical interventions [3].

Fig. 1: Showing distance from alveolar crest to M.F.

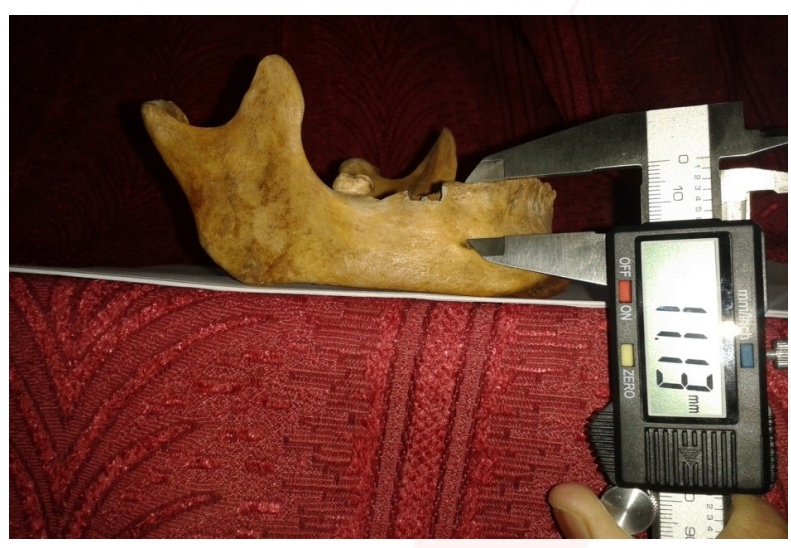

Fig. 2: Specimen showing the parameters measured.

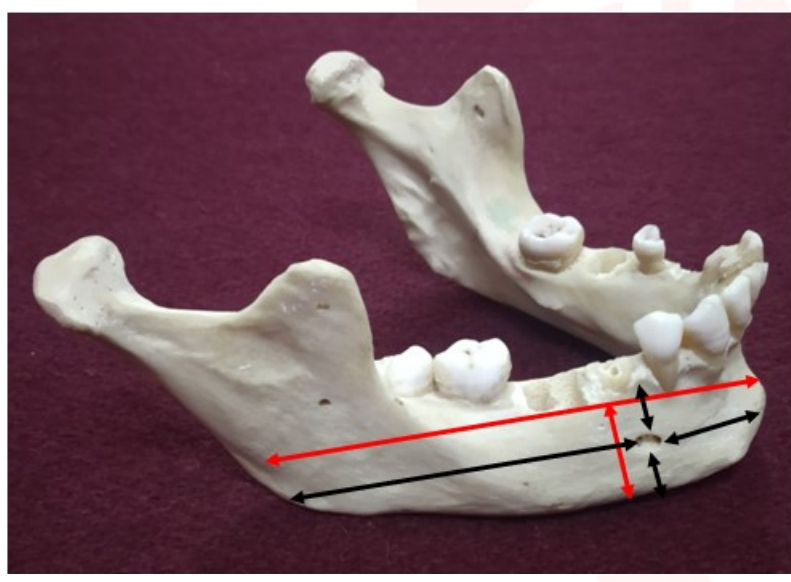

\section{MATERIALS AND METHODS}

A total of 100 adult dry human mandibles were collected from the department of Anatomy, Khaja Banda Nawaz institute of medical sciences, Faculty of Medicine, Khaja Banda Nawaz University, Gulbarga, Karnataka. Both sides of the mandibles were assessed. The size, shape and position of the right and left side of the mandible were recorded by direct visual inspection and digital vernier calipers (Fig. 1). We measured the distance of MF (in $\mathrm{mm}$ ) considering following landmarks which includes symphysis menti, alveolar crest, posterior border of the ramus of mandible, and lower border of mandible with digital vernier caliper and calculated the size of mental foramen (Fig. 2).
The following parameters are considered during measurements.

AC: distance from alveolar crest to upper margin of mental foramen (Fig. 1).

BD: distance from lower border of mandible to lower margin of mental foramen.

$A B$ : distance from alveolar crest to lower border of mandible.

$V D$ : vertical diameter of foramen $V D=A B$ " $(A C+B D)$.

WY: distance from symphysis menti to medial margin of mental foramen.

$\mathrm{XZ}$ : distance from posterior border of ramus of mandible to lateral margin of mental foramen.

WX: distance from symphysis menti to posterior border of ramus of mandible.

HD: horizontal diameter of foramen $\mathrm{HD}=W X^{\text {“ }}$ (WY + XZ).

\section{RESULTS}

Table 1: Comparison of v.d \& h.d between present \& other studies.

\begin{tabular}{|c|c|c|c|c|}
\hline \multirow{2}{*}{ Authors } & \multicolumn{2}{|c|}{ H.D (mean) } & \multicolumn{2}{c|}{ V.D (mean) } \\
\cline { 2 - 5 } & Right & Left & Right & Left \\
\hline Oguz \& bozkir 2002 [7] & $2.93 \mathrm{~mm}$ & $3.14 \mathrm{~mm}$ & $2.38 \mathrm{~mm}$ & $2.64 \mathrm{~mm}$ \\
\hline Singh \& srivastav 2010 [8] & $2.79 \mathrm{~mm}$ & $2.57 \mathrm{~mm}$ & - & - \\
\hline Agarwal \&gupta 2011 [9] & $3.33 \mathrm{~mm}$ & $3.25 \mathrm{~mm}$ & $2.15 \mathrm{~mm}$ & $2.13 \mathrm{~mm}$ \\
\hline Present study 2017-2019 & $5.01 \mathrm{~mm}$ & $5.01 \mathrm{~mm}$ & $2.90 \mathrm{~mm}$ & $2.82 \mathrm{~mm}$ \\
\hline
\end{tabular}

Table 2: Comparison of shape of m.f. between present \& other studies.

\begin{tabular}{|c|c|c|}
\hline \multirow{2}{*}{ Authors } & \multicolumn{2}{|c|}{$\begin{array}{c}\text { Shape of mental } \\
\text { foramen in \% }\end{array}$} \\
\cline { 2 - 3 } & Oval & Round \\
\hline Singh \& srivastav 2010 [8] & $6 \%$ & $94 \%$ \\
\hline Agarwal \& gupta 2011 [9] & $92 \%$ & $8 \%$ \\
\hline Mbajiorgu et.al 1998 [10] & $56.30 \%$ & $43.80 \%$ \\
\hline Present study 2017-2019 & $64 \%$ & $36 \%$ \\
\hline
\end{tabular}

Table 3: Comparison of position of M.F between present \& other studies.

\begin{tabular}{|c|c|c|}
\hline Authors & Position of mf & $\begin{array}{c}\text { \%of most common } \\
\text { position of mf }\end{array}$ \\
\hline Singh \& srivastav 2010 [8] & Below apex of $2^{\text {nd }} \mathrm{pm}$ & $68.80 \%$ \\
\hline Wang et al 1986 [11] & Below apex of $2^{\text {nd }} \mathrm{pm}$ & $58.98 \%$ \\
\hline Santini \& land 1990 [12] & Below apex of $2^{\text {nd }} \mathrm{pm}$ & $52.90 \%$ \\
\hline Agarwal \& gupta 2011 [9] & Below apex of $2^{\text {nd }} \mathrm{pm}$ & $81.55 \%$ \\
\hline Present study 2017-2019 & Below apex of $2^{\text {nd }} \mathrm{pm}$ & $58 \%$ \\
\hline
\end{tabular}

Table 4: Location of mental foramen.

\begin{tabular}{|c|c|c|c|}
\hline Side & $\mathbf{1}^{\text {st }}$ and $\mathbf{2}^{\text {nd }}$ PMT & $2^{\text {nd }}$ PMT & $\mathbf{2}^{\text {nd }}$ PMT and $\mathbf{1}^{\text {st }} \mathbf{M T}$ \\
\hline Right & $26 \%$ & $58 \%$ & $16 \%$ \\
\hline Left & $24 \%$ & $46 \%$ & $30 \%$ \\
\hline
\end{tabular}




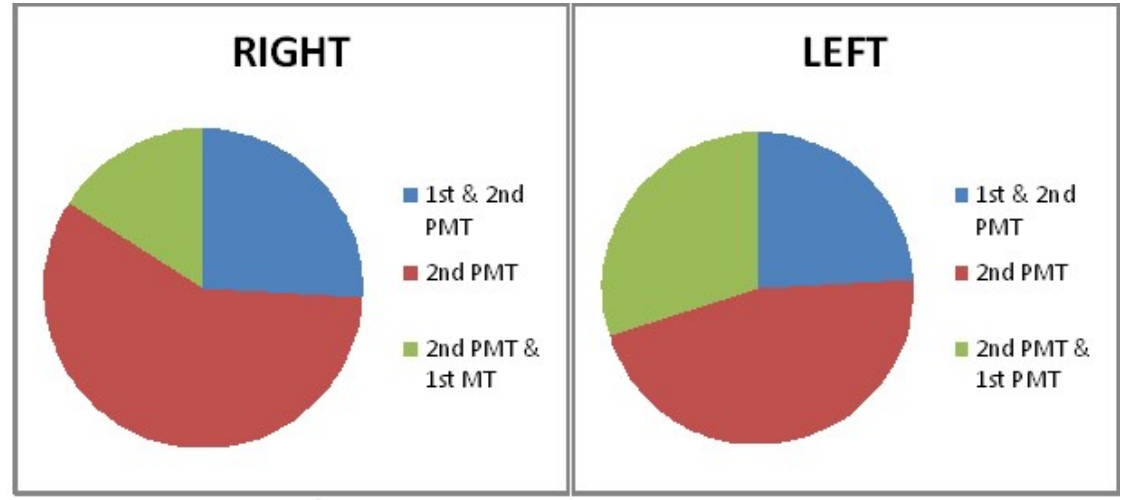

Table 5: Parameters to measure vertical diameter of mental foramen.

\begin{tabular}{|c|c|c|c|c|c|c|c|c|}
\hline Parameter & \multicolumn{2}{|c|}{ AC } & \multicolumn{2}{c|}{ BD } & \multicolumn{3}{c|}{ AB } & \multicolumn{2}{c|}{ VD } \\
\hline & Right & Left & Right & Left & Right & Left & Right & Left \\
\hline Mean & 11.28 & 11.34 & 14.85 & 14.72 & 29.04 & 28.89 & 2.9 & 2.82 \\
\hline S. D & 0.81 & 0.78 & 0.51 & 0.77 & 0.87 & 0.9 & 0.64 & 0.61 \\
\hline
\end{tabular}

The results are expressed as mean and standard deviations. The position of MF was classified in relation to teeth of the lower jaw in accordance with Tebo and Telford [4].

I. Foramen lying on a longitudinal axis passing between canine and first premolar;

II. Foramen lying on the longitudinal axis of first premolar;

III. Foramen lying on a longitudinal axis passing between first and second premolars;

IV. Foramen lying on longitudinal axis of second premolar;

V. Foramen lying on a longitudinal axis passing between second premolar and first molar;

VI. Foramen lying on longitudinal axis of first molar.

\section{DISCUSSION}

Ukoha et.al in south eastern Nigerian described most common shape round in their studies [5] (Table 2) Olasoji et al in North Nigerians described the most common location of MF is between first and second premolars [6] (Table 3). Oguz and Bozkir did measurements in 34 dry mandibles of people from Turkey and found a mean HD of $2.93 \mathrm{~mm}$ on the right side and 3.14 $\mathrm{mm}$ on the left side, and a mean VD of $2.38 \mathrm{~mm}$ and $2.64 \mathrm{~mm}$ on the right and left sides, respectively [7]. In another study conducted by Singh and Srivastav, only the HD was taken and the results showed the mean $\mathrm{HD}$ to be $2.79 \mathrm{~mm}$ on the right side and $2.57 \mathrm{~mm}$ on the left side less than the present study [8] (Table 5). Agarwal \& Gupta et al studied on 100 mandibles in gujarat population. Mean H.D was $3.33 \mathrm{~mm}$ on right side and $3.25 \mathrm{~mm}$ on left side, mean V.D was 2.15 $\mathrm{mm}$ on right side and $2.13 \mathrm{~mm}$ on left side (Table 1). The most frequent position of foramen in relation to the teeth was in line with the longitudinal axis of 2 nd premolar for both right (81.55\%) and left (81.50\%) sides. The shape of foramen was oval in $92 \%$ cases and rounded in $8 \%$ cases [9].

\section{CONCLUSION}

The most common position of MF is below the apex of second premolar, second most common position is between first and second premolars followed by third most common position between the second premolar and first molar (Table $3 \& 4$ ). The knowledge of distances surgically encountered anatomical landmark and effective localization of neurovascular bundle passing through MF will provide valuable information to dental surgeons that will facilitate mental foramen thus avoiding complications from local anesthetic, surgical and other invasive procedures.

\section{ABBREVATIONS}

PM - Pre Molar

MT - Molar Tooth

MF - Mental Foramen

AC - Distance between alveolar crest of mandible and upper margin of MF

BD - Distance between lower border of mandible and lower margin of MF

AB - Distance from alveolar crest to lower border of mandible 
VD - Vertical diameter of $M F=A B$ “ $(A C+B D)$

WY - Distance from symphysis menti to medial margin of MF.

XZ - Distance from posterior border of ramus of mandible to lateral margin of MF.

WX - Distance from symphysis menti to posterior border of ramus of mandible.

HD - Horizontal diameter of MF = WX " (WY + $\mathrm{XZ)}$.

\section{Conflicts of Interests: None}

\section{REFERENCES}

[1]. Williams, P. L.; Bannister, L. H.; Berry, M. M.; Collins, P.; Dyson, M. \& Dussek, J. E. Gray's Anatomy: The anatomical basis of medicine and surgery. 38th Ed. New York, Churchill Livingstone, 2000.

[2]. Kjaer, I. Formation and early prenatal location of the human mental foramen. Scand. J. Dent. Res., 97:1-7, 1989.T. W. Sadler- Langman's Medical Embryology. $11^{\text {th }}$ edt. 2009, 144-145.

[3]. Julian, R. D. \& Chapel Hill, N. C. Position of the mental foramen in a North American, white population. Oral Surg. Oral Med. Oral Pathol. Oral Radiol. Endod., 1998;85:457-60.

[4]. H. G. Tebo and I. R. Telford. An analysis of the variations in position of the mental foramen. the Anatomical Record, 1950;107(1):61-66.

[5]. Ukoha Ukoha Ukoha et. al Position, shape and direction of the mental foramen in mandibles in South -Eastern Nigeria Int J of Biomedical Research 2013;4(9):499-503.
[6]. Olasoji HO, Tahir A, Ekanem AU, Abubakar AA. Radiographic and anatomic locations of mental foramen in northern Nigerian adults. Niger Postgrad Med J 2004;11:230-3.

[7]. O. Oguz and M. G. Bozkir. Evaluation of location of mandibular and mental for foramina in dry, young, adult human male,dentulous mandibles. West Indian Medical Journal 2002;51(1):14-16.

[8]. R. Singh and A. K. Srivastav. Study of position, shape, size and incidence of mental foramen and accessory mental foramen in Indian adult human skulls. International Journal of Morphology, 2010;28(4):1141-1146.

[9]. D. R. Agarwal and S. B. Gupta. Morphometric analysis of mental foramen in human mandibles of south Gujarat. People's Journal of Scientific Research 2011;4(1):15-18.

[10]. Mbajiorgu EF, Mawera G, Asala SA, Zivanovic S Position of the mental foramen in adult black Zimbabwean mandibles: a clinical anatomical study. Central African journal of medicine 1998 Feb;44(2):24-30.

[11]. Wang TM, Shih C, Liu JC, Kuo KJ. A clinical and anatomical study of the location of the mental foramen in adult Chinese mandibles. Acta anatomica. 1986;126(1):29-33.

[12]. Santini, A. \& Land, M. A comparison of the position of themental foramen in Chinese and British mandibles. ActaAnat. (Basel) 1990;137:20S-12.

How to cite this article:

Mohammad Khaleel Ahmed, Syed Nazeer Ahmed, Humaira Zainab. THE SHAPE, SIZE AND POSITION OF MENTAL FORAMEN IN HUMAN DRIED MANDIBLE IN THE KALABURAGI REGION. Int J Anat Res 2020;8(1.3):7367-7370. DOI: 10.16965/ijar.2020.105 